\title{
Mechanisms of Catalytic Activity in Heavily Coated Hydrocracking Catalysts
}

\author{
M. Millan*, C. Adell, C. Hinojosa, A.A. Herod and R. Kandiyoti \\ Department of Chemical Engineering, Imperial College London, London SW7 2AZ - UK \\ e-mail: marcos.millan@imperial.ac.uk -crisadell@hotmail.com - cecyhglori@hotmail.com - a.herod@imperial.ac.uk - r.kandiyoti@imperial.ac.uk \\ * Corresponding author
}

Résumé - Étude de mécanismes de l'activité des catalyseurs d'hydrocraquage avec fort cokage La désactivation des catalyseurs par cokage a un impact direct sur la viabilité économique des procédés de raffinage d'hydrocarbures lourds, tels que la liquéfaction du charbon et l'hydrotraitement des résidus pétroliers. Le cokage est responsable de la perte rapide de l'activité du catalyseur qui a lieu principalement au début de l'hydrocraquage. Dans ce travail, les effets sur l'activité catalytique liés aux dépôts de carbone ont été étudiés sur un catalyseur à base d'argile de type chrome-montmorillonite. L'activité catalytique lors de l'hydrocraquage d'un extrait de charbon a été évaluée par la méthode de distribution des points d'ébullition des produits et réactifs. Ces derniers furent analysés par thermogravimétrie (TGA), puis caractérisés par chromatographie d'exclusion stérique (SEC) et spectroscopie de fluorescence. Lors de deux expériences successives de 2 heures chacune et pour lesquelles le catalyseur fût réutilisé, il a été constaté que la Cr-montmorillonite conservait toute son activité. Ceci en dépit d'un dépôt important de carbone, d'une diminution de sa surface d'échange et d'une obstruction apparente de ses pores. Certaines observations peuvent contribuer à l'explication de cette persistance de l'activité catalytique. Tout d'abord, des indications suggèrent l'aspect dynamique des dépôts de carbone, qui échangeraient continuellement de la matière avec la phase liquide, permettant ainsi à l'activité catalytique de perdurer. Ensuite, une analyse par microscopie électronique à balayage (MEB) de la Cr-montmorillonite, exposée lors des expériences, montre un dépôt localisé sur certaines zones du catalyseur, laissant ainsi une partie de la surface relativement libre. Enfin, les résultats de MEB couplé à un spectromètre $\mathrm{X}$, suggèrent aussi que les dépôts sont plus clairsemés sur les zones où la phase active du catalyseur est en forte concentration. L'hydrogénation au niveau des sites actifs rendrait les dépôts plus solubles dans la phase liquide, libérant ainsi les zones adjacentes aux sites actifs.

\begin{abstract}
Mechanisms of Catalytic Activity in Heavily Coated Hydrocracking Catalysts - Catalyst deactivation by coke deposition has a direct impact on the economic viability of heavy hydrocarbon upgrading processes, such as coal liquefaction and oil residue hydroprocessing. Coke deposition is responsible for rapid loss of catalytic activity and it mostly takes place in the early stages of hydrocracking. The effect of carbonaceous deposition on the catalytic activity of a chromium pillared montmorillonite has been studied in the present work. Its catalytic activity in hydrocracking a coal extract was evaluated based on the boiling point distributions of feed and products obtained by thermogravimetric analysis (TGA), and their characterisation by size exclusion chromatography (SEC) and $U V$-Fluorescence spectroscopy $(U V-F)$. A large deposition on the catalyst was observed after two
\end{abstract}


successive 2-hour long runs in which the catalyst recovered from the first run was reused in the second. The pillared clay retained its activity even though it showed high carbon loading, a large drop in surface area and complete apparent pore blockage. Some observations may contribute to explain this persistent catalytic activity. First, there is evidence suggesting the dynamic nature of the carbonaceous deposits, which continuously exchange material with the liquid, allowing catalytic activity to continue. Secondly, Scanning Electron Microscopy (SEM) on the used Cr montmorillonite has shown preferential deposition on some regions of the catalyst, which leaves a fraction of the surface relatively exposed. Finally, evidence from SEM coupled to X-ray microanalysis also suggest that deposits are thinner in areas where the active phase of the catalyst is present in higher concentrations. Hydrogenation on the active sites would make the deposits more soluble in the liquid clearing a surrounding area from deposits.

\section{INTRODUCTION}

Three main mechanisms leading to catalyst deactivation have been identified: deactivation by coke deposition or "fouling", by metals and by pore mouth constriction and blockage $[1,2]$. Coke deposition occurs in the early stages of hydroprocessing and it reaches a pseudo steady state, whereas deactivation by metal deposits continues over a longer time scale [2-4]. Pore blockage becomes relevant at later stages and it is irreversible, forcing the end of the run and the regeneration or replacement of the catalyst.

The effect of coke deposition on the deactivation process is more marked than that of metal deposits. The deactivation effect of metals has been qualitatively described as very weak on hydrogenation and weak on the cracking function. By contrast, the effect of coke deposition on the catalytic activity was regarded as strong on hydrogenation and very strong on cracking [5]. The study of catalyst deactivation in the present work focuses on deactivation by coke deposition.

The pore size of hydrocracking catalysts was reported to be an important factor in hydrocracking and heteroatom removal of asphaltenes and preasphaltenes [6]. Larger pores improve the access to the catalyst by the larger molecules present in these feeds. In an attempt to design materials which can accommodate larger molecules, pillared clays were tested in this laboratory $[7,8]$. In these compounds, the separation between clay layers is modified by inserting an ion, which must provide both structural stability and an adequate gap between layers to allow the reactants to diffuse into the catalyst. These catalysts exhibit a high permanent porosity. A lower pillar density leads to bigger galleries in the catalyst, which would favour the access of larger molecules into the catalyst pores. However, a high pillar density provides higher mechanical stability. Hence catalyst design must involve a compromise between these two factors.

Pillared clays have been tested in several applications: as catalysts for heavy oil upgrading [9-11], polyethylene catalytic cracking [12], denox processes [13], clean up of aqueous environments $[14,15]$ and sorption of humic substances [16].
In an earlier screening study, some pillared clays showed promising levels of activity as catalysts for coal and oil hydrocracking $[7,8]$. In these studies, a chromium montmorillonite was identified as one of the most effective catalysts among them in reducing the molecular sizes in the feedstock [7].

A new set of pillared clays were developed in subsequent work [17]. These catalysts included tin and chromium-pillared laponites and montmorillonites prepared by different methods. Their hydrocracking performances have been presented elsewhere [17]. This work aims to study in more detail the effect of carbonaceous deposition on CM3, one of the Crmontmorillonites tested. Possible explanations for its sustained activity despite the heavy carbonaceous coating are suggested in this paper.

\section{EXPERIMENTAL}

\subsection{Hydrocracking Experiments}

The hydrocracking reactions were carried out in a microbomb reactor described in previous work [19]. The experimental conditions applied to catalyst testing were $19 \mathrm{MPa}$ hydrogen pressure and $440^{\circ} \mathrm{C}$. A coal liquefaction extract from a pilot plant operated by British Coal at Point of Ayr, Wales, in the late 80's and early 90's was used as feed in this work. The Point of Ayr (PoA) liquid extract has been extensively analysed in previous work in this laboratory $[31,32]$.

$1 \mathrm{~g}$ of sample and $250 \mathrm{mg}$ of catalyst were used in each run. The reactor was immersed in a fluidised sand bath heater where it reached $440^{\circ} \mathrm{C}$, being subsequently kept at that temperature for two hours. After this period, the reactor was removed from the sand bath, cooled down to ambient temperature and depressurised. It was then washed with a mixture of chloroform and methanol $(4: 1 \mathrm{v} / \mathrm{v})$ to recover all liquid and solid products. This reaction mixture in $\mathrm{CHCl}_{3} / \mathrm{CH}_{3} \mathrm{OH}$ was filtered to separate the soluble products from the solids, consisting of catalyst coated with carbonaceous 
deposits. Millipore glass filter holder with Whatman No. 1 qualitative filter paper was used. The catalyst was thoroughly washed with chloroform:methanol mixture in order to remove the soluble materials. Afterwards, it was dried in a vacuum oven at $60^{\circ} \mathrm{C}$ for 3 hours to eliminate $\mathrm{CHCl}_{3} / \mathrm{CH}_{3} \mathrm{OH}$ and weighed. The carbonaceous content of the solids was measured by thermogravimetric analysis (TGA) as described below. Scanning electron microscopy (SEM) was also run on the coated catalyst sample.

Regarding the soluble products, the $\mathrm{CHCl}_{3} / \mathrm{CH}_{3} \mathrm{OH}$ mixture was evaporated using a rotary evaporator until a $\mathrm{CHCl}_{3} / \mathrm{CH}_{3} \mathrm{OH}$ content lower than $1 \%$ is reached. The sample weight was then recorded. Small portions of this sample are used for TGA-based boiling point determination, size exclusion chromatography (SEC) and UV-fluorescence (UV-F).

The catalysts coated with carbonaceous materials were reused in a second two-hour experiment to hydrocrack fresh Point of Ayr liquefaction extract, following the same experimental procedure described above. These experiments aimed to simulate in a batch reactor the conditions found in commercial operation, where coated catalyst is continuously exposed to fresh feed.

The synthesis of the Cr-montmorillonite, which was performed by a partner group at Aston University, has been described elsewhere [17]. A commercial $\mathrm{NiMo} / \mathrm{Al}_{2} \mathrm{O}_{3}$ (PBC90) was employed as reference catalyst.

\subsection{Conversion}

Assessment of the catalysts was based on their ability to hydrocrack the fraction of the feed with boiling point above $450^{\circ} \mathrm{C}$ into lighter materials. Conversion has been defined in previous work $[8,18]$ as:

$$
\text { Conversion }=\frac{w_{\text {feed }} \cdot\left(f_{>450^{\circ} \mathrm{C}}\right)_{\text {feed }}-w_{\text {liq }} \cdot\left(f_{>450^{\circ} \mathrm{C}}\right)_{\text {liq }}-w_{\text {sol }} \cdot \Delta f_{\text {carb }}}{w_{\text {feed }} \cdot\left(f_{>450^{\circ} \mathrm{C}}\right)_{\text {feed }}}
$$

where $w_{\text {feed }}, w_{\text {liq }}$ and $w_{\text {sol }}$ are the weights of feed, liquid products, and solids recovered after hydrocracking respectively. $\left(f_{>450^{\circ} \mathrm{C}}\right)_{\text {feed }}$ and $\left(f_{>450^{\circ} \mathrm{C}}\right)_{\text {liq }}$ are the fractions of material with boiling point above $450^{\circ} \mathrm{C}$ (" $>450^{\circ} \mathrm{C}$ ") in the feed $(38 \%)$ and liquid products respectively. $\Delta f_{\text {carb }}$ is the fraction of carbonaceous layer due to "new" deposition on the catalyst, i.e. without taking into account the amount of carbonaceous material present on the catalyst at the beginning of the run. This definition of conversion includes the solids deposited on the catalyst as part of the " $>450^{\circ} \mathrm{C}$ " fraction in the products. This correction is performed to avoid obtaining apparently high conversions just by removal of " $>450^{\circ} \mathrm{C}$ " material as deposits on the catalyst rather than by actual hydrocracking.

The " $>450^{\circ} \mathrm{C}$ " fractions in feed and products were determined by TGA employing a simulated distillation method developed in this laboratory [19]. Briefly, the method consists in heating the sample under a flow of helium and mea- suring the fraction evaporated as a function of temperature. A calibration which relates the temperature on the TGA pan at which volatilisation occurs with boiling point is used. This method overcomes limitations of the standard simulated distillation based on gas chromatography (GC), as this coal extract contains a heavier fraction composed by materials too large to elute through a GC column. The carbonaceous content of the used catalysts was also determined by TGA [19].

\subsection{UV-Fluorescence Spectroscopy}

Synchronous, emission and excitation UV-fluorescence (UVF) spectra have been obtained in a Perkin-Elmer LS50 Luminescence Spectrometer operated in the static-cell mode. To record the emission spectrum the sample was excited at a constant wavelength and the emission recorded in the full range of wavelengths. The excitation spectrum was obtained by varying the excitation frequency while keeping the recording wavelength fixed. In the synchronous spectrum both excitation and emission are simultaneously varied. In this case, the wavelength difference between excitation and emission is kept constant at $20 \mathrm{~nm}$. In this mode, fluorescence of sample solutions in NMP has been measured between 250 and $800 \mathrm{~nm}$. The samples were scanned at $240 \mathrm{~nm} / \mathrm{min}$.

\subsection{Size Exclusion Chromatography}

The size exclusion chromatography (SEC) system and its calibrations have been described elsewhere [20,21]. Briefly, a polystyrene/polydivinylbenzene SEC "Mixed-A" column from Polymer Laboratories Ltd was used in this work. The eluent was N-methyl pyrrolidinone (NMP) at a flow rate of $0.5 \mathrm{~mL} / \mathrm{min}$. Detection was performed by ultraviolet absorption at five wavelengths $280,300,350,370$ and $450 \mathrm{~nm}$ and evaporative light scattering. The area under the chromatograms was normalised employing software developed in this laboratory in order to facilitate comparison between runs in which different sample concentrations were used.

\subsection{Surface Area Measurements}

A Micromeritics 2000 ASAP surface area analyser was used in surface area measurements. Approximately $200 \mathrm{mg}$ of sample were used for each analysis. The standard method based on the adsorption of nitrogen on the surface was applied [22]. Beforehand, the samples were dried overnight at $150^{\circ} \mathrm{C}$ in a vacuum oven in order to remove moisture and adsorbed gases from the catalyst pores. The method developed by Brunauer, Emmett and Teller (BET method) to calculate the surface area was applied. Pore size distributions were obtained by the BHJ method (developed by Barret, Halenda and Joyner) based on the desorption isotherm. 


\subsection{Scanning Electron Microscopy and X-ray Microanalysis}

A JEOL JSM 840 scanning electron microscope (SEM) has been employed. Its maximum resolution is $10 \mathrm{~nm}$ and it is capable of quantifying elements present in the sample by X-ray microanalysis to an accuracy of within $0.1 \%$. Elemental data can be presented either as a table showing the composition in a given number of points over the sample or as maps of surface concentration of the elements.

The samples were coated beforehand with a thin layer of carbon to improve electrical conductivity over the surface. This layer is sufficiently thin $(150 \AA)$ and uniform to avoid confusion with the carbonaceous deposition during the hydrocracking process.

$\mathrm{X}$-ray microanalysis has been carried out on the catalyst surface to identify the elemental composition of the sample. The X-ray analysis is performed over a $0.8 \mathrm{~m}$ sided square and it penetrates 3 to $4 \mu \mathrm{m}$ under its surface. The SEM and $\mathrm{X}$-ray microscopy detectors are located in different positions. As a consequence, some zones of the SEM micrograph which appear dark may show signal in the elemental distribution and vice versa.

\section{RESULTS AND DISCUSSION}

\subsection{Activity of the CM3 Cr-montmorillonite}

As mentioned above, several pillared clays have been tested as hydrocracking catalysts [17]. Catalysts were evaluated in terms of conversions of the material with boiling point above $450^{\circ} \mathrm{C}$ into lighter products. Molecular mass distributions and relative sizes of fused aromatic rings in the products were determined by SEC and UV-F respectively. The Cr-montmorillonite CM3 was the best performing among the pillared clays tested and was therefore selected for further studies on the mechanisms of its catalytic activity carried out in this paper. Two successive 2-hour long experiments were carried out; the catalyst recovered from the first run was reused, without removal of the deposits, in a second 2-hour experiment. The conversions achieved in those experiments are shown in Table 1. Conversions obtained employing a commercial $\mathrm{NiMo} / \mathrm{Al}_{2} \mathrm{O}_{3}$ are also shown for comparison.

A large deposition of carbonaceous material on the fresh CM3 was observed during the first run. Carbonaceous deposits represented $35 \%$ of the total solids recovered after this run, the remaining $65 \%$ being catalyst. When the CM3 catalyst was reused, conversion increased from 29\% (fresh catalyst) to $45 \%$. Although the increase in conversion observed in the second run may appear counter-intuitive, this is a consequence of the large deposition observed in the first run. It must be noted that according to the definition of conversion applied in this work, material deposited on the catalyst is not counted as converted. As mentioned above, this is in order to distinguish active hydrocracking catalysts from materials on which a large fraction of the feed would simply be adsorbed. Therefore, the conversion is relatively small in the first run, when the deposition is large, at the point of being only marginally better than that found in the non-catalysed run. A smaller deposition (4\%) took place on the already coated catalyst. A similar effect was observed for the commercial $\mathrm{NiMo} / \mathrm{Al}_{2} \mathrm{O}_{3}$. The level of conversion achieved with $\mathrm{CM} 3$ in the second run was as high as that obtained with $\mathrm{NiMo} / \mathrm{Al}_{2} \mathrm{O}_{3}$.

TABLE 1

Conversion and deposition on the catalyst for $\mathrm{CM} 3$ and $\mathrm{NiMo} / \mathrm{Al}_{2} \mathrm{O}_{3}$ in two successive two-hour long runs

\begin{tabular}{c|c|c|c|c}
\hline & \multicolumn{2}{|c|}{ 1st run } & \multicolumn{2}{c}{ 2nd run } \\
\hline Catalyst & $\begin{array}{c}\text { Carbonaceous } \\
\text { deposits }\left(\Delta f_{\text {carb }}\right)\end{array}$ & Conversion & $\begin{array}{c}\text { Carbonaceous } \\
\text { deposits }\left(\Delta f_{\text {carb }}\right)\end{array}$ & Conversion \\
\hline $\mathrm{CM} 3$ & 35 & 29 & 4 & 45 \\
\hline $\mathrm{NiMo} / \mathrm{Al}_{2} \mathrm{O}_{3}$ & 26 & 36 & 16 & 45 \\
\hline No catalyst & - & 21 & - & - \\
\hline
\end{tabular}

The activity of $\mathrm{CM} 3$ as hydrocracking catalyst is also supported by UV-F and SEC analyses of the products. The SEC chromatograms of the Point of Ayr liquefaction extract

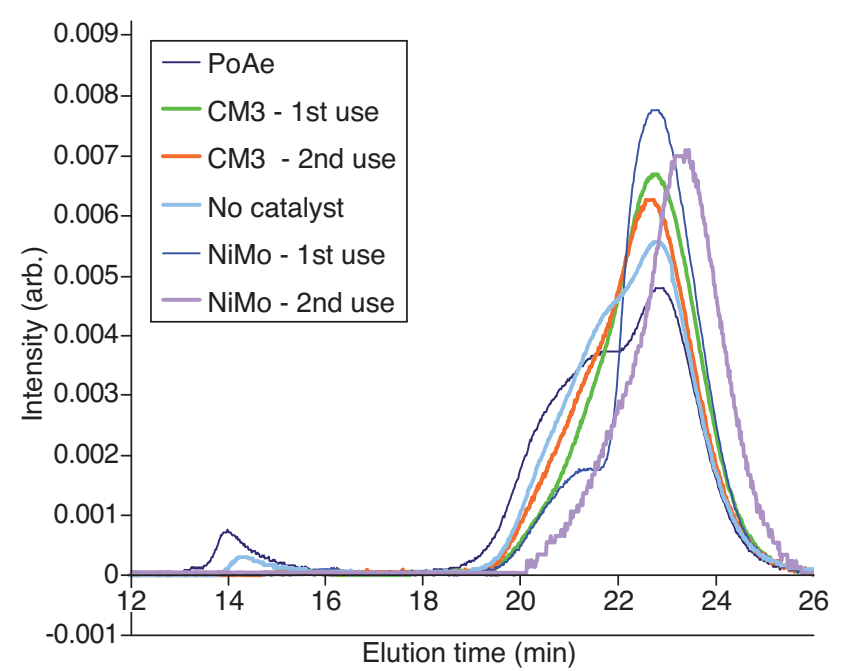

Figure 1

SEC chromatogram of the feed (POAe) and hydrocracking products from runs using $\mathrm{NiMo} / \mathrm{Al}_{2} \mathrm{O}_{3}, \mathrm{CM} 3$ and no catalyst. Only detection by UV absorbance at $300 \mathrm{~nm}$ is shown. 


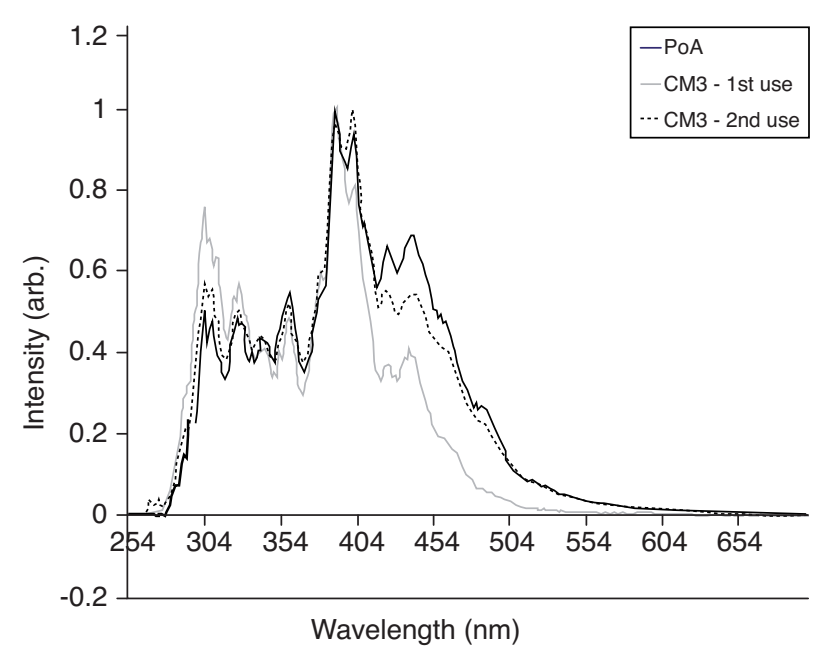

Figure 2

Synchronous UV-F spectra of the feed (PoAe) and hydrocracking products from runs using $\mathrm{CM} 3$ and no catalyst.

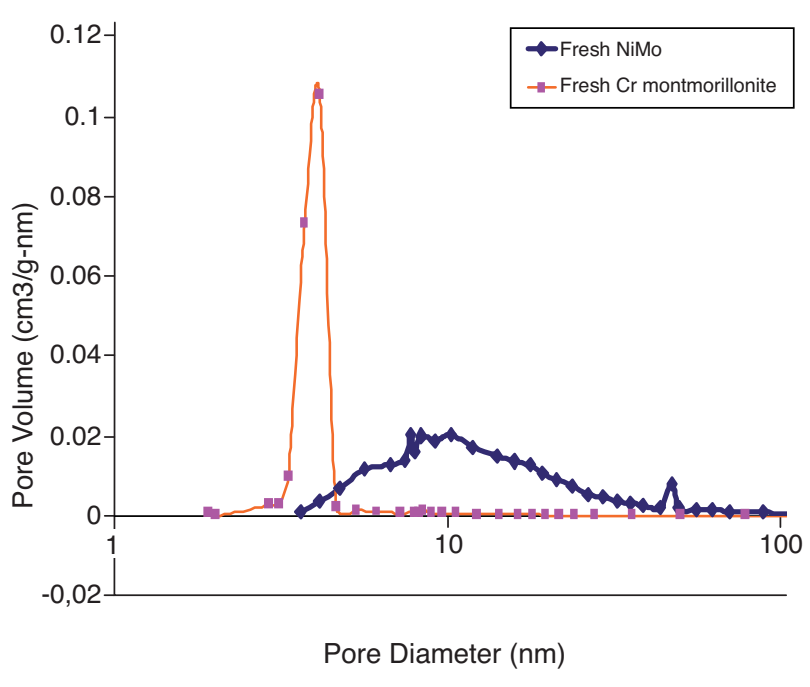

Figure 3

Pore size distributions of fresh $\mathrm{NiMo} / \mathrm{Al}_{2} \mathrm{O}_{3}$ and $\mathrm{CM} 3$.
(POAe) and the liquid products from the reaction catalysed by $\mathrm{CM} 3$ and $\mathrm{NiMo} / \mathrm{Al}_{2} \mathrm{O}_{3}$ are shown in Figure 1 . The chromatogram of the hydrocracking products obtained without catalyst is also shown for comparison. The excluded peak disappeared and the retained peak shifted towards longer elution times (smaller molecular sizes) than that of the feed for all products from the catalysed reactions. The shifts towards smaller sizes achieved with the reused CM3 was not as large as after the first use.

UV-F spectroscopy was applied in the qualitative analysis of relative sizes of polynuclear aromatic rings in these samples. The synchronous UV-F spectra of the products from the runs catalysed with CM3 showed shifts towards shorter wavelengths than the spectrum of the feed (Fig. 2), indicating a decrease in the size of aromatic rings in the products relative to the feed. The shift to shorter wavelengths was smaller in the second run than in the first use of the catalyst, suggesting the presence of larger aromatic rings in the second run products.

Summarising, CM3 proved to be still active after 4 hours of use, despite its high carbonaceous content. The conversions achieved with the reused catalyst increased relative to the first use, although the liquid products obtained seemed to be slightly heavier. These results may be due to the lower deposition levels in the second run, which would leave a larger part of the " $>450^{\circ} \mathrm{C}$ " fraction in solution.

\subsection{Effect of Coke Deposition on the Physical Properties of the Catalysts}

CM3 exhibited a larger surface area than the $\mathrm{NiMo} / \mathrm{Al}_{2} \mathrm{O}_{3}$. However, the pore size distribution of the fresh $\mathrm{NiMo} / \mathrm{Al}_{2} \mathrm{O}_{3}$ was much broader than that of $\mathrm{CM} 3$ as shown in Figure 3. While the $\mathrm{NiMo} / \mathrm{Al}_{2} \mathrm{O}_{3}$ showed a distribution centred at $9 \mathrm{~nm}$ and expanding up to nearly $50 \mathrm{~nm}$, a very narrow pore diameter distribution was observed in the pillared clay. The fresh CM3 has a large pore volume in pore diameters ranged from 3 to $5 \mathrm{~nm}$, but negligible pore volume is found outside this range. A sharp drop in the surface area of the Cr-montmorillonite was observed after 4 hours in operation. The surface area of the catalyst recovered from the reactor was in the order of $1 \mathrm{~m}^{2} / \mathrm{g}$, although it must be noted that the experimental error in measuring such a small surface area is large.

After 4 hours hydrocracking, the porosity of the pillared clay decreased to about a thousandth of that of the fresh catalysts. The small pores appeared to have been blocked by the deposits. No reliable total pore volume and average pore diameter were obtained for the used pillared clay as their values were too small.

There is then an apparent contradiction between the sustained catalytic activity of the chromium montmorillonite catalyst and its drastic reduction in surface area and pore volume within the first four hours on stream. Some observations that may contribute to understand this phenomenon are presented 


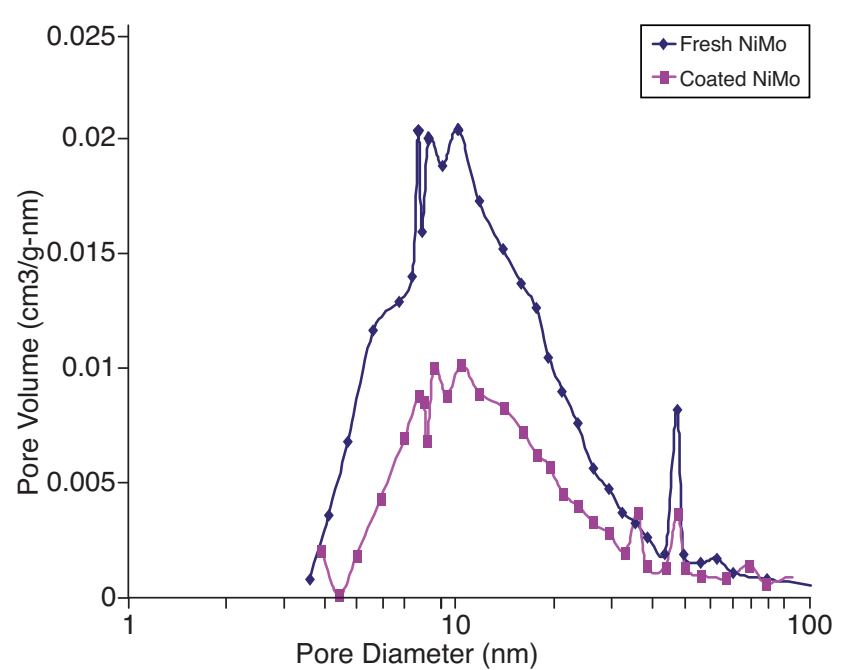

Figure 4

Pore size distributions of fresh and coated $\mathrm{NiMo} / \mathrm{Al}_{2} \mathrm{O}_{3}$.

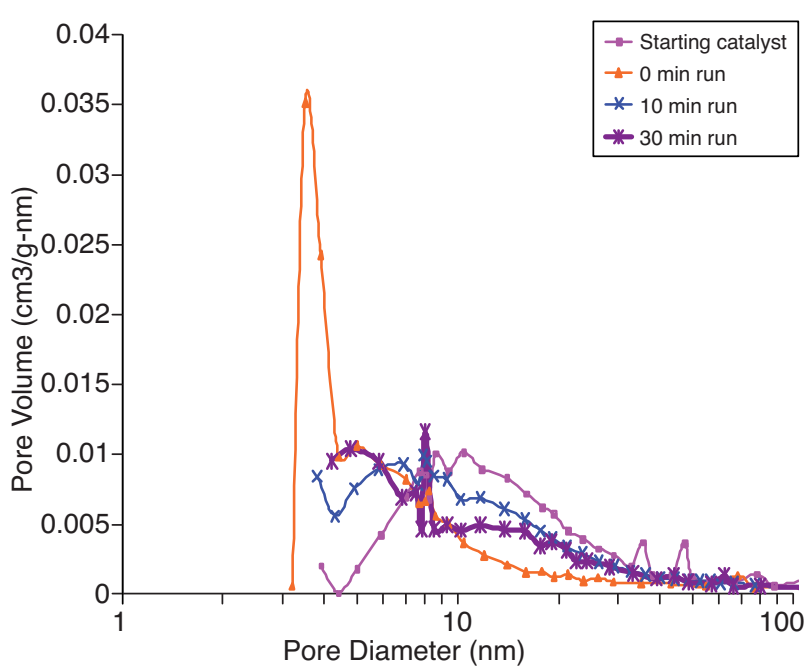

Figure 5

Pore size distribution of the starting catalyst (coated $\mathrm{NiMo} / \mathrm{Al}_{2} \mathrm{O}_{3}$ ) and the catalysts recovered from the reactor after 0,10 and 30 minutes. below. They include the dynamic nature of the carbonaceous deposits, the preferential deposition on some regions of the catalyst and the hydrogenating effect of the $\mathrm{Cr}$ active sites, which clear from deposits a surrounding area. These explanations should be considered additional to the mechanism of hydrogen shuttle through the carbonaceous layer proposed in early work [30].

\subsubsection{The Dynamic Nature of the Carbonaceous Deposits}

Studies on the hydrocracking of coal extracts at different reactions times using a commercial $\mathrm{NiMo} / \mathrm{Al}_{2} \mathrm{O}_{3}$ catalyst [18] suggest that the deposits are dynamic and a continuous exchange of large amounts of material between the liquid and the catalyst surface take place. The $\mathrm{NiMo} / \mathrm{Al}_{2} \mathrm{O}_{3}$ catalyst was coated with a carbonaceous deposit beforehand in order to study the interaction between fresh feed and a catalyst which has been on stream for some time. Catalyst preparation and these experiments have been described elsewhere [18].

Figure 4 shows the pore size distribution of the $\mathrm{NiMo} / \mathrm{Al}_{2} \mathrm{O}_{3}$ before and after coating. Although coating produced a general decrease in the pore volume for all pore diameters, the shape of the distribution remained similar to that of the fresh catalyst. A sharper drop in pore volume is observed in the region of pore diameters between 4 and $8 \mathrm{~nm}$. The maxima of both distributions were at nearly $10 \mathrm{~nm}$.
The coated $\mathrm{NiMo} / \mathrm{Al}_{2} \mathrm{O}_{3}$ was then used as catalyst in 0 , 10 and 30 minute runs. After the " 0 minute" (heat-up only) hydrocracking run, significant changes in the pore size distribution of the catalyst were observed (Fig. 5). There was a net decrease in the volume of pores around $10 \mathrm{~nm}$ while a remarkable increase in volume was observed for pores of $5 \mathrm{~nm}$ in diameter and below. It seems that the initial deposition on the catalyst tended to produce pore mouth constriction and reduce the size of the larger pores.

The deposits showed a dynamic behaviour and the reduction in pore diameter was partially reversed between 0 and 10 minutes. The volume of the smaller pores (below $5 \mathrm{~nm}$ ) decreased and that of pores with diameters between 5 and $20 \mathrm{~nm}$ increased. This reflected on the average pore diameter, which increased from 7.3 to $10 \mathrm{~nm}$ measured by BET. The change in the pore size distribution was associated with a reduction in the amount of deposits. The total surface area remained constant within these 10 minutes. More complete data on surface area have been presented in reference [18].

Between 10 and 30 minutes the volume of the larger pores slightly decreased whereas that of the smaller ones increased marginally. This is in line with other works suggesting a gradual built-up of carbonaceous deposits on the catalyst after the initial deposition [23, 24]. The BET average pore diameter showed a small decrease from 10.2 to $9.4 \mathrm{~nm}$ and the surface area showed no changes. 


\subsubsection{Preferential Deposition on Some Regions of the Catalyst}

Samples of CM3 after the first and second use have been examined by scanning electron microscopy and X-ray microanalysis. SEM and $\mathrm{X}$ ray microscopy of CM3 after the 1st use are shown in Figure 6. The large scale SEM image (Fig. 6a) showed a relatively large extent of carbonaceous deposition (in red in the micrograph). However, when the scale is magnified it is possible to observe that the carbonaceous layer was preferentially deposited in some regions. Figure $6 \mathrm{~b}$, shows the distribution of carbon in red and those of $\mathrm{Si}$ and $\mathrm{Al}$ in green and blue respectively. Five points in that micrograph were selected (Fig. 6c) to measure elemental composition by X-ray microscopy. This analysis revealed C:Si ratios varying from 2.7 to 44.7, as indicated in Table 2. This shows that the carbonaceous layer was not uniformly distributed and that despite the large overall deposition some areas of the catalyst were still accessible.

TABLE 2

$\mathrm{Al}: \mathrm{Si}$ and $\mathrm{C}: \mathrm{Si}$ ratio measured by $\mathrm{X}$-ray microscopy in five points shown in Figure 6c

\begin{tabular}{c|c|c}
\hline Point No. & Al:Si ratio & C:Si ratio \\
\hline 1 & 0.31 & 6.2 \\
\hline 2 & 0.12 & 23.0 \\
\hline 3 & 0.31 & 23.5 \\
\hline 4 & 0.20 & 2.7 \\
\hline 5 & 0.21 & 44.7 \\
\hline
\end{tabular}

\subsubsection{Activity of Chromium Sites Clearing an Area Surrounding the Active Site}

The CM3 was reused and SEM and X-ray microscopy after 2nd use are presented in Figure 7. Figure 7a shows several catalyst particles and the $\mathrm{Cr}$ concentration mapped in red. $\mathrm{Cr}$ does not seem evenly distributed; there are some zones with particularly high concentration. The carbonaceous deposition is heavy in some regions as can be observed in the carbon profile (Fig. $7 b$ ). Si, $\mathrm{Al}$ and $\mathrm{O}$ showed similar profiles among themselves reflecting the composition of the clay particles (Figs. 7c, $d$, and $e$, respectively).

A region centred in the zone of higher $\mathrm{Cr}$ concentration was magnified. Figure $7 \mathrm{f}$ shows the carbonaceous deposits (blue), the $\mathrm{Cr}$ concentration (red) and the silica in the clay (green). At this smaller scale, it is obvious that the deposits are not uniformly distributed.

The carbonaceous layer seems to be thinner in areas where the $\mathrm{Cr}$ concentration is higher. This result is in line with observations of preferential carbonaceous deposition on the catalyst support presented in the literature [25-27]. A model proposed by Diez et al. [28] suggested that the hydrogenation on the active sites clears a surrounding area from deposits. Richardson et al. [29] found that this model successfully fitted the dependence of coke deposition on hydrogen pressure, reaction time, feed to catalyst ratio and feed composition. The lack of homogeneity in the deposits may suggest that chromium has high hydrogenating activity, and may provide an explanation for the persistent catalytic activity observed even though the deposition levels were high.

\section{CONCLUSIONS}

CM3, a Cr-pillared montmorillonite, exhibited an interesting level of hydrocracking activity, comparable to that of a $\mathrm{NiMo} / \mathrm{Al}_{2} \mathrm{O}_{3}$ commercially used. Surface area measurements showed that this pillared clay catalyst had a larger surface area than the commercial $\mathrm{NiMo} / \mathrm{Al}_{2} \mathrm{O}_{3}$ used as reference. However, it showed a much narrower pore diameter distribution, concentrated in the region between 3 and $5 \mathrm{~nm}$.

After 4 hours in operation both the surface area and the porosity of CM3 showed a marked decrease, consistent with the large deposition of carbonaceous materials measured by TGA. On the other hand, the $\mathrm{NiMo} / \mathrm{Al}_{2} \mathrm{O}_{3}$ catalyst showed more resistance to drops in surface area and pore blockage, likely due to its larger pore size distribution.

Some observations that may help to understand the sustained activity of the CM3 are presented in this work. Firstly, the carbonaceous layer is dynamic and an active exchange with the bulk liquid takes place, at least within these first few hours. Moreover, the carbonaceous materials seem to deposit preferentially over some zones of the catalyst, leaving other regions still relatively exposed after 4 hours of operation. In addition, some SEM micrographs show that regions with higher $\mathrm{Cr}$ contents might present lower deposits. This suggests that the presence of hydrogenation activity in the $\mathrm{Cr}$ sites clears a surrounding area from deposits. This behaviour in the active sites has been reported previously in the literature for NiMo catalysts [28, 29 ] and a similar effect could partially explain the persistent activity of the CM3 catalyst in spite of the high levels of carbonaceous deposits.

\section{ACKNOWLEDGEMENTS}

We thank our partners at Aston University, Dr Elma Gyftopoulou and Prof Tony Bridgwater for the supply of the $\mathrm{Cr}$ montmorillonite used in this work. Funding from EPSRC under Grant GR/R27471/01 is gratefully acknowledged. 

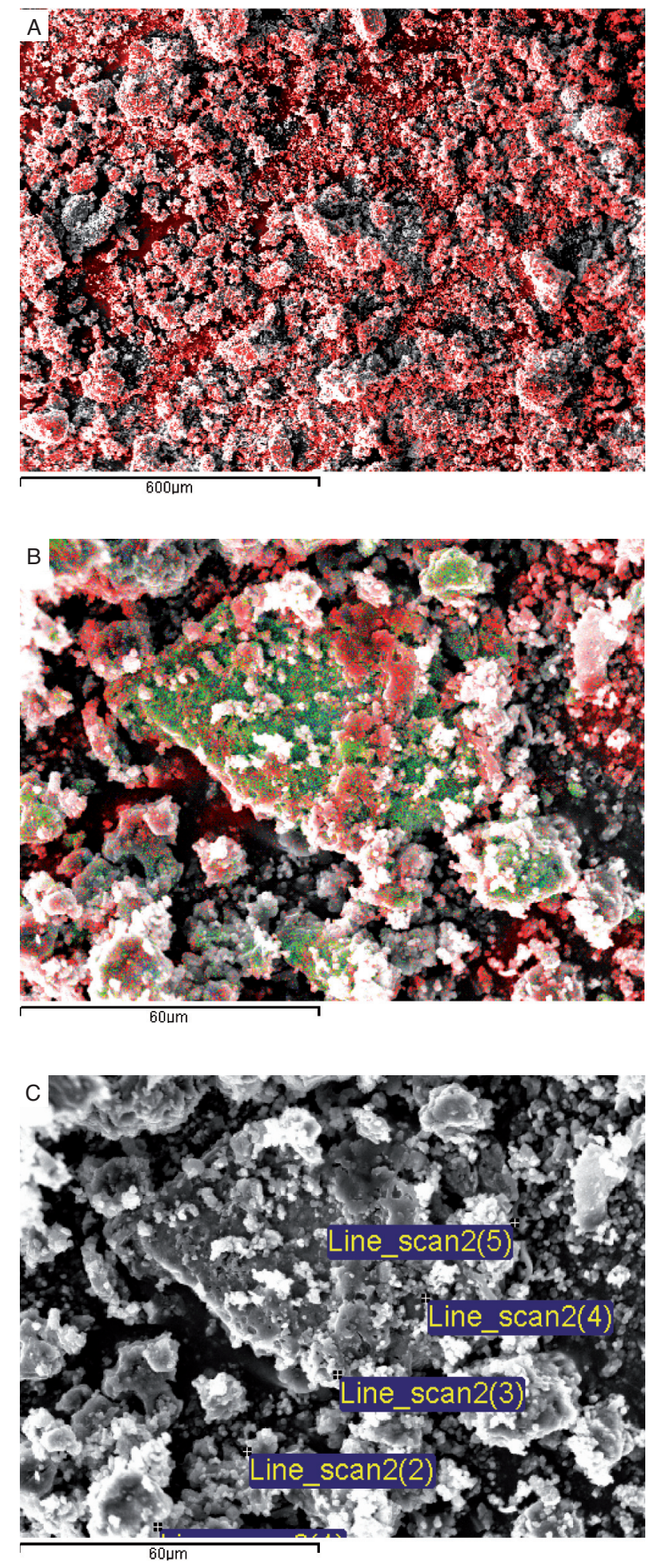

Figure 6

SEM micrographs of CM3 used once. (a) shows the carbonaceous deposition in red; (b) shows the carbon distribution (red), silicon (green) and aluminium (blue); (c) five points taken for the determination of elemental compositions shown in Table 2.

\section{REFERENCES}

1 Absi-Halabi M., Stanislaus A., Trimm D.L. (1991) Coke formation on catalysts during the hydroprocessing of heavy oils, Appl. Catal. 72, 193-215.

2 Furimsky E., Massoth F.E. (1999) Deactivation of hydroprocessing catalysts, Catal. Today 52, 381-495.

3 Ancheyta J., Betancourt G., Centeno G., Marroquin G., Alonso F., Garciafigueroa E. (2002) Catalyst Deactivation during Hydroprocessing of Maya Heavy Crude Oil. 1. Evaluation at Constant Operating Conditions, Energ. Fuel. 16, 1438-1443.

4 Ancheyta J., Betancourt G., Centeno G., Marroquin G. (2003) Catalyst Deactivation during Hydroprocessing of Maya Heavy Crude Oil. II. Effect of Temperature during Time-on-Stream, Energ. Fuel. 17, 462-467.

5 Cable T.L., Massoth F.E., Thomas M.G. (1981) Studies on an aged H-coal catalyst, Fuel Process. Technol. 4, 265-275.

6 Song C., Hanaoka K., Nomura M. (1992) Influence of Pore Structure and Chemical Properties of Supported Mo Catalysts on Their Performance in Upgrading Heavy Liquids, Energ. Fuel. 6, 619-628.

7 Bodman S.D., Mc Whinnie W.R., Begon V., Suelves I., Lazaro M.J., Morgan T.J., Herod A.A., Kandiyoti R. (2002) Metal-ion pillared clays as hydrocracking catalysts (I): Catalyst preparation and assessment of performance at short contact times, Fuel $\mathbf{8 1}$, 449-459.

8 Bodman S.D., Mc Whinnie W.R., Begon V., Millan M., Suelves I., Lazaro M.J., Herod A.A., Kandiyoti R. (2003) Metal-ion pillared clays as hydrocracking catalysts (II): effect of contact time on products from coal extracts and petroleum distillation residues, Fuel 82, 2309-2321.

9 Olson E.S., Sharma R.K. (1996) Naphthene Upgrading with Pillared Synthetic Clay Catalysts, Energ. Fuel. 10,587-590.

10 De Stefanis A., Perez G., Lilla E., Ursini O., Tomlinson A.A.G. (2001) Conversions of resins and asphaltenes in porous catalysts, J. Anal. Appl. Pyrol. 57, 37-44.

11 Occelli M.L., Schweizer A.E., Fild C., Schwering G., Eckert H., Auroux A. (2000) Gallioaluminosilicate Molecular Sieves with the Faujasite Structure, J. Catal. 192, 119-127.

12 Manos G., Yusof I.Y., Gangas N.H., Papayannakos N. (2002) Tertiary Recycling of Polyethylene to Hydrocarbon Fuel by Catalytic Cracking over Aluminium Pillared Clays, Energ. Fuel. 16, 485-489.

13 Grzybek T., Klinik J., Olszewska D., Papp H., Smarzowski (2001) The influence of montmorillonite treatment on structure, sorption properties and catalytic behaviour: Part I. Zirconia pillared clays modified with manganese as denox catalysts, J. Pol. J. Chem. 75, 857-868.

14 Meier L.P., Nueesch R., Madsen F.T. (2001) Organic pillared clays, J. Colloid Interf. Sci. 238, 24-32.

15 Gultek A., Seckin T., Onal Y., Icduygu M.G. (2001) Preparation and phenol captivating properties of polyvinylpyrrolidinone-montmorillonite hybrid materials, J. Appl. Polym. Sci. 81, 512-519.

16 Lacey A.L., Hayes M.H.B., Vaidyanathan L.V. (1997) Preparation of iron pillared clays and their applications for sorption of humic substances, in Humic Substances in Soils, Peats and Waters, Hayes and Wilson. RSC, pp. 219-225.

17 Gyftopoulou M.E., Millan M., Bridgwater A.V., Dugwell D., Kandiyoti R., Hriljac J.A. (2005) Pillared clays as catalysts for hydrocracking of heavy liquid fuels, Appl. Catal. A-Gen. 282, 205-214. 

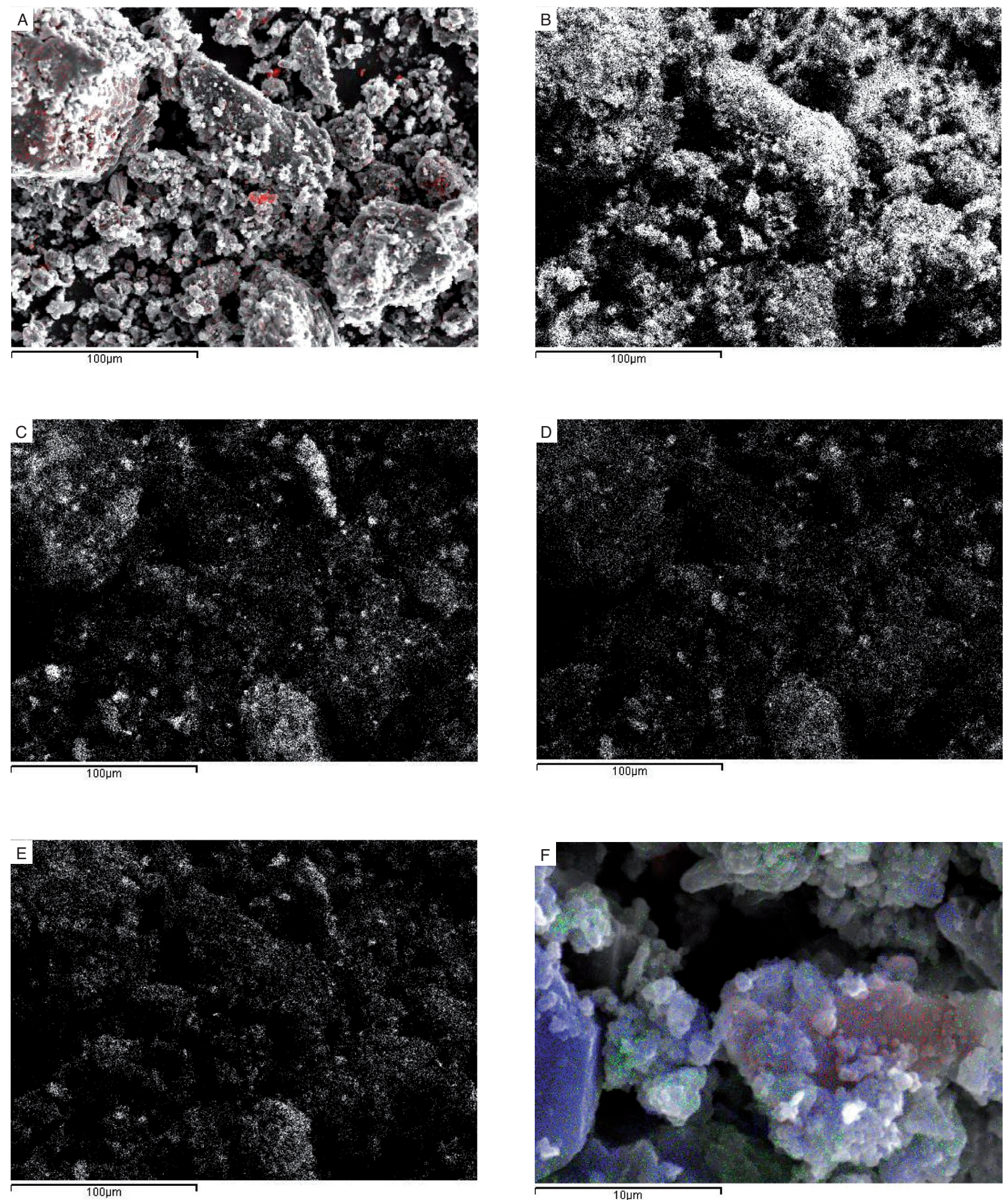

Figure 7

(a) SEM of the CM3 used twice; the Cr distribution is shown in red; (b) Carbon X-ray microanalysis profile; (c) Si X-ray microanalysis profile; (d) Aluminium X-ray microanalysis profile; (e) Oxygen X-ray microanalysis profile; (f) The area richer in Cr is magnified; X-ray microanalysis profiles of carbon (blue), silicon (green) and chromium (red) are shown. 
18 Millan M., Adell C., Hinojosa C., Herod A.A., Dugwell D., Kandiyoti R. (2007) Effect of Catalyst Deactivation and Reaction Time on Hydrocracking Heavy Hydrocarbon Liquids, Energ. Fuel. 21, 3, 1370-1378.

19 Zhang Sheng-fu., Xu Bin., Herod A.A., Kandiyoti R. (1996) Hydrocracking reactivities of primary coal extracts prepared in a flowing-solvent reactor, Energ. Fuel. 10, 733-742.

20 Lazaro M.J., Islas C.A., Herod A.A., Kandiyoti R. (1999) Calibration of Size Exclusion Chromatography in 1-Methyl-2Pyrrolidinone for Coal-Derived Materials Using Standards and Mass Spectrometry, Energ. Fuel. 13, 1212-1222.

21 Karaca F., Islas C.A., Millan M., Behrouzi M., Morgan T.J., Herod A.A., Kandiyoti R. (2004) The calibration of size exclusion chromatography columns: Molecular mass distributions of heavy hydrocarbon liquids, Energ. Fuel. 18, 778-788.

22 McDonnell M.E., Walsh E.K. (1988) A guide to materials characterization and chemical analysis, Sibila John P. (ed.), VCH Publishers, pp. 257-261.

23 Begon V., Megaritis A., Lazaro M.J., Herod A.A., Dugwell D.R., Kandiyoti R. (1998) Changes in sample reactivity and catalyst deactivation during early stages of the hydrocracking of a coal extract, Fuel 77, 1261-1272.

24 Yoshimura Y., Sato T., Shimada H., Nishijima A. (1986) Fuel Sci.Technol. Int. 4, 621 .

25 Fleisch T.H., Meyers B.L., Hall J.B., Ott G.L. (1984) Multitechnique analysis of a deactivated resid demetallation catalyst, J. Catal. 86, 147-157.
26 van Doorn J., Moulijn J.A. (1993) A Model of Coke on Hydrotreating Catalysts under Reaction Conditions, Fuel Process. Technol.35, 275-287.

27 van Doorn J., Moulijn J.A., Djega-Mariadassou G. (1990) Highresolution Electron Microscopy of Spent Ni-Mo/A1203 Hydrotreating Catalysts, Appl. Catal. 63, 77-90.

28 Diez F., Gates B.C., Miller J.T., Sajkowski D.J., Kukes S.G. (1990) Deactivation of a NiMo-A- $\mathrm{Al}_{2} \mathrm{O}_{3}$ catalyst: Influence of coke on the hydroprocessing activity, Ind. Eng. Chem. Res. 29, 1999-2004.

29 Richardson S.M., Nagaishi H., Gray M.R. (1996) Initial Coke Deposition on a NiMo/ $\gamma-\mathrm{Al}_{2} \mathrm{O}_{3}$ Bitumen Hydroprocessing Catalyst, Ind. Eng. Chem. Res. 35, 3940-3950.

30 Thomson S.J., Webb G. (1976) Catalytic hydrogenation of olefins on metals: a new interpretation, J. Chem. Soc. Chem. Commun. 13, 526-527.

31 Islas C.A., Suelves I., Carter J.F., Herod A.A., Kandiyoti R. (2000) Pyrolysis-gas chromatography/mass spectrometry of a coal extract and its fractions separated by planar chromatography: correlation of structural features with molecular mass, Rapid Commun. Mass Sp. 14, 1766-1782.

32 Islas C.A., Suelves I., Li W., Morgan T.J., Herod A.A., Kandiyoti R. (2003) The unusual properties of high mass materials from coal derived liquids, Fuel 82, 1813-1823.

Final manuscript received in October 2007 or distributed for profit or commercial advantage and that copies bear this notice and the full citation on the first page. Copyrights for components of this work owned by others than IFP must be honored. Abstracting with credit is permitted. To copy otherwise, to republish, to post on servers, or to redistribute to lists, requires prior specific permission and/or a fee: Request permission from Documentation, Institut français du pétrole, fax. +33147527078 , or revueogst@ifp.fr. 